\title{
Aging skeletal muscle shows a drastic increase in the small heat shock proteins $\alpha \mathrm{B}$-crystallin/HspB5 and cvHsp/HspB7
}

\author{
Philip Doran, Joan Gannon, Kathleen O’Connell, Kay Ohlendieck*
}

Department of Biology, National University of Ireland, Maynooth, Co. Kildare, Ireland

Received 2 May 2007; received in revised form 30 June 2007; accepted 4 July 2007

\begin{abstract}
Most heat shock proteins operate as molecular chaperones and play a central role in the maintenance of normal cellular function. In skeletal muscle, members of the $\alpha$-crystallin domain-containing family of small heat shock proteins are believed to form a cohort of essential stress proteins. Since $\alpha \mathrm{B}$-crystallin $(\alpha \mathrm{BC} / \mathrm{HspB} 5)$ and the cardiovascular heat shock protein (cvHsp/HspB7) are both implicated in the molecular response to fibre transformation and muscle wasting, it was of interest to investigate the fate of these stress proteins in young adult versus aged muscle. The agerelated loss of skeletal muscle mass and strength, now generally referred to as sarcopenia, is one of the most striking features of the senescent organism. In order to better understand the molecular pathogenesis of age-related muscle wasting, we have performed a two-dimensional gel electrophoretic analysis, immunoblotting and confocal microscopy study of aged rat gastrocnemius muscle. Fluorescent labelling of the electrophoretically separated soluble muscle proteome revealed an overall relatively comparable protein expression pattern of young adult versus aged fibres, but clearly an up-regulation of $\alpha \mathrm{BC}$ and cvHsp. This was confirmed by immunofluorescence microscopy and immunoblot analysis, which showed a dramatic age-induced increase in these small heat shock proteins. Immunodecoration of other major stress proteins showed that they were not affected or less drastically changed in their expression in aged muscle. These findings indicate that the increase in muscle-specific small heat shock proteins constitutes an essential cellular response to fibre aging and might therefore be a novel therapeutic option to treat sarcopenia of old age.

(C) 2007 Elsevier GmbH. All rights reserved.
\end{abstract}

Keywords: Aging; alpha-B crystallin; cvHsp; sHsp; Heat shock protein; Sarcopenia

\section{Introduction}

The rapid synthesis of the highly conserved group of heat shock proteins (Hsps) is triggered by diverse stresses, including elevated temperatures, exposure to toxins, inflammation, ischemia and hypoxia (Lindquist and Craig, 1988). Hsp genes contain in their promotor

\footnotetext{
*Corresponding author. Tel.: + 35317083842 ; fax: +35317083845 .

E-mail address: kay.ohlendieck@nuim.ie (K. Ohlendieck).
}

region a consensus-binding sequence for the heat shock factor HSF1 (Amin et al., 1988), which is the transcription factor generally associated with acute cellular stress (Anckar and Sistonen, 2007). Most Hsps function as chaperones and their essential role is to maintain normal cellular function by interacting with malfolded proteins thereby preventing their aggregation into large deleterious complexes (Voellmy and Boellmann, 2007). Besides adding the renaturation process of malfolded proteins, Hsps also influence the intracellular transport of mature proteins. In muscle tissues, Hsps are essential for cell 
survival during injury (Liu and Steinacker, 2001; Nishimura and Sharp, 2005). The physiological response to stressful conditions in muscle fibres involves highmolecular-mass Hsps such as Hsp70 (McArdle et al., 2004; Liu et al., 2006), as well as a set of small heat shock proteins (sHsps) ranging in monomer size from 16 to $25 \mathrm{kDa}$ (Nicholl and Quinlan, 1994; Koh and Escobedo, 2004; Haslbeck et al., 2005). A subfamily of 10 sHsps exists in mammalians (de Jong et al., 1993; Kappe et al., 2003) and they are characterized by a conserved carboxy-terminal sequence, the 90-residue ' $\alpha$-crystallin' domain (van Montfort et al., 2001; Narberhaus, 2002; Stamler et al., 2005). Besides the formal names HspB1 to HspB10, these small stress proteins have been given numerous descriptors over the last few years of hsp research (Sun et al., 2004; Fontaine et al., 2005; Ikeda et al., 2006).

This study has focused on HspB5, which is more commonly known as $\alpha \mathrm{B}$-crystallin ( $\alpha \mathrm{BC}$; Horwitz, 2003) and $\mathrm{HspB}$ 7, originally named cardiovascular heat shock protein (cvHsp; Krief et al., 1999). Crystallins represent major structural proteins of the eye lens, making up more than $90 \%$ of its total dry mass, and are responsible for the refractive power of the lens (Horwitz, 2000). However, the expression of $\alpha \mathrm{BC}$ is not restricted to the lens, but this sHsp also exists in heart, skeletal muscle, skin, lung and the central nervous system (Dubin et al., 1989; Iwaki et al., 1990; Oertel et al., 2000). Primary abnormalities in $\alpha \mathrm{BC}$ were shown to play a crucial pathological role in cataractogenesis, neuropathy and desmin-related myopathy (Takemoto and Boyle, 1998; Vicart et al., 1998; van Rijk and Bloemendal, 2000; Sun and MacRae, 2005). In contrast to the relatively broad cellular distribution of $\alpha \mathrm{BC}$, its related chaperone cvHsp appears to be restricted to heart and skeletal muscle tissues as shown by cell biological and developmental studies (Verschuure et al., 2003; Golenhofen et al., 2004). Interestingly, fibre type shifting following chronic low-frequency stimulation of fast muscles (Neufer and Benjamin, 1996; Donoghue et al., 2005) and muscular dystrophy-induced changes in the dystrophin-deficient diaphragm muscle (Doran et al., 2006a) are associated with a drastic increase in $\alpha \mathrm{BC}$ and cvHsp, respectively. Since the elevated expression level of cvHsp was more pronounced in 11-month-old dystrophic mouse diaphragm as compared to 9-week-old mdx mutant fibres (Doran et al., 2007), it was of interest to investigate the fate of cvHsp and $\alpha \mathrm{BC}$ during normal muscle aging.

A great variety of cellular, physiological and molecular alterations have been described to occur during skeletal muscle aging, including excitation-contraction uncoupling, oxidative stress, increased apoptosis, disturbed microcirculation, mitochondrial abnormalities, altered synthesis rate for key muscle proteins, hormonal imbalance, impaired ion homeostasis and a diminished regenerative potential (Navarro et al., 2001; Vandervoort,
2002; Doherty, 2003). The pathobiochemical hierarchy within these various degenerating pathways is not well understood (Carmeli et al., 2002). The drastic loss of both muscle mass and function in the senescent organism has been termed sarcopenia of old age, which can be considered a progressive state of cellular dysfunction (Greenlund and Nair, 2003). An established animal model of sarcopenia is represented by 30-monthold rat skeletal muscle (Kanski et al., 2005). Since a recent proteomic study of rat muscle has shown similar protein expression patterns between young and mature adult fibres, but severe alterations in old animals (Piec et al., 2005), we have here compared 3-month-old versus 30-month-old rats, representing young adult versus senescent skeletal muscles, respectively.

High-resolution two-dimensional gel electrophoretic analysis in combination with immunoblotting clearly illustrated a drastic increase in $\alpha \mathrm{BC}$ and cvHsp expression in aged muscle, which was confirmed by immunofluorescence microscopy. This age-related stress response in skeletal muscle may relate to the structural and metabolic alterations associated with sarcopenia (McArdle and Jackson, 2000). Up-regulation of sHsps may represent an auto-protective mechanism of damaged muscle fibres (Koh, 2002) and counteract the disintegration of the contractile apparatus and may facilitate the transformation to an aerobic-oxidative metabolism. Thus, in analogy to the established changes in Hsp expression during myogenic differentiation, sustained neuromuscular activity, hyperthermia and muscular disorders (Nishimura and Sharp, 2005), fibre aging is also associated with a drastic modification in stress protein levels.

\section{Materials and methods}

\section{Materials}

Protease inhibitors were purchased from Roche Diagnostics (Mannheim, Germany). Chemicals and materials for gel electrophoresis, including the 2-D Quant kit for protein quantification, 24-cm IPG strips (pH 3-10), IPG ampholytes (pH 3-10) and fluorescent protein dye Deep Purple stock solution were obtained from Amersham Biosciences/GE Healthcare (Little Chalfont, Bucks., UK). Primary antibodies were from Visionbiosystems Novocastra, Newcastle upon Tyne, UK (mAb G2JF to $\alpha$ B-crystallin; mAb 8D5 to $\beta$-dystroglycan), Hytest Ltd., Turku, Finland (pAb to cvHsp), StressGen Bioreagents, Victoria, Canada (pAb SPA-796 to Hsp20; pAb SPA-801 to Hsp25; mAb LK-2 to Hsp60; mAb BB70 to Hsp70; and $\mathrm{mAb} 16 \mathrm{~F} 1$ to Hsp90) and Sigma, Dorset, UK (pAb to laminin). The antibody to Hsp70 recognizes both the inducible form 
(Hsp70/Hsp72) and the constitutive form (Hsc70/ Hsp73) of this stress protein. Peroxidase-conjugated secondary antibodies were purchased from Chemicon International (Temecula, CA, USA) and Alexa Fluorconjugated secondary antibodies were from Invitrogen Molecular Probes (Bio Sciences Ltd., Dun Laoghaire, Ireland). Diamidino-phenylindole (DAPI) was from Sigma. Nitrocellulose membranes were purchased from Millipore (Bedford, MA, USA) and chemiluminescence substrate was from Pierce and Warriner (Chester, UK). For peptide mass fingerprinting analysis, trypsin was obtained from Promega (Madison, WI, USA). External calibration peptide mixture $\mathrm{A}$ and a matrix kit containing $\alpha$-cyano-4-hydroxycinnamic were from Laserbiolabs, Sophia-Antipolis, France. All other chemicals were of analytical grade and obtained from Sigma.

\section{Rat model of sarcopenia}

The gastrocnemius muscle from 30-month-old Wistar rats was used as an established animal model of sarcopenia and compared to young adult muscle from 3-month-old Wistar rats. Freshly dissected muscle specimens were obtained from the Animal Facility of the Department of Physiology, Trinity College Dublin. Rats were kept at a standard light-dark cycle and fed ad libitum (Nolan et al., 2005). With respect to activity levels, both young adult and old rats used in this study were not specifically trained, but were unrestricted in their movement in standard animal house cages. The activity level of the older rat population was reduced as compared to the younger cohort. The suitability of aged rat muscle as a model system to study sarcopenia has been previously shown by various cell biological, physiological and anatomical studies. Aging clearly affects fibre type proportions, fibre size and contractile properties (Larsson and Edstrom, 1986). Aged rat muscle exhibits a variety of abnormal features, including a higher frequency of longitudinal splitting and fibre degeneration (Alnaqeeb and Goldspink, 1987). The decrease in the number of fibres appears to be due to the loss of whole motor units (Edstrom and Larsson, 1987), whereby denervation-reinnerevation cycles result in the incomplete recruitment of aged fibres (Larsson et al., 1991). A recent study by Cutlip et al. (2007) showed that age impairs the ability of rat muscle to properly adapt to repetitive mechanical loading. Changes in the contractile properties of both slow- and fast-twitching muscle seem to relate to the reduced speed of contraction in sarcopenia (Larsson and Edstrom, 1986).

\section{Preparation of total skeletal muscle extracts}

Muscle aliquots of $100 \mathrm{mg}$ wet weight were quickfrozen in liquid nitrogen and ground into a fine powder using a mortar and pestle, and subsequently placed into $1 \mathrm{ml}$ lysis buffer containing $7 \mathrm{M}$ urea, $2 \mathrm{M}$ thiourea, $20 \mathrm{mM}$ Tris, $4 \%(\mathrm{w} / \mathrm{v})$ CHAPS, $100 \mathrm{mM}$ DTT and $2 \%$ (v/v) $\mathrm{pH}$ 3-10 ampholytes. The buffer was supplemented with a protease inhibitor cocktail $(0.5 \mathrm{mM}$ soybean trypsin inhibitor, $0.2 \mathrm{mM}$ pefabloc, $1 \mu \mathrm{M}$ leupetin, $1.4 \mu \mathrm{M}$ pepstatin, $0.15 \mu \mathrm{M}$ aprotinin, $0.3 \mu \mathrm{M}$ E-64 and $1 \mathrm{mM}$ EDTA). Incubation, centrifugation and protein precipitation was carried out as recently described in detail (Donoghue et al., 2005). The extracted total protein complement from young adult and senescent muscles was resuspended in $1 \mathrm{ml}$ lysis buffer each and its protein content measured with the Amersham 2-D Quant kit.

\section{Gel electrophoresis}

One-dimensional (1-D) sodium dodecyl sulfate polyacrylamide gel electrophoresis (SDS-PAGE) was carried out by a method optimized for the separation of skeletal muscle proteins (Harmon et al., 2001). For the comparative two-dimensional (2-D) gel electrophoretic analysis of young adult versus senescent gastrocnemius muscle protein complement, total extracts were separated in the first dimension by isoelectric focusing and in the second dimension by SDS-PAGE, as previously described in detail (Doran et al., 2004). Isoelectric focusing strips were rehydrated in $7 \mathrm{M}$ urea, $2 \mathrm{M}$ thiourea, $20 \mathrm{mM}$ Tris, $4 \%$ (w/v) CHAPS, $100 \mathrm{mM}$ DTT and $2 \%(\mathrm{v} / \mathrm{v}) \mathrm{pH} \mathrm{3-10}$ ampholytes for $12 \mathrm{~h}$ and then loaded gel side up in an Ettan IPGphor manifold (Amersham Biosciences/GE Healthcare). Using anodic cup loading, $500 \mu \mathrm{g}$ of total protein sample from young adult or aged rat muscle, was added to the IPG pH 3-10 strips and separated on an Amersham IPGphor IEF system employing standard electrophoretic running conditions (Doran et al., 2006b). Following chemical reduction, alkylation and washing in SDS-containing running buffer, first-dimension strips were placed on top of $12.5 \%(\mathrm{w} / \mathrm{v})$ separating gels and electrophoresed in an Amersham Ettan DALT-Twelve system until the blue tracker dye front had just ran off the lower edge of second-dimension gel (Doran et al., 2006a). Twodimensional gels were then used for total protein stain analysis and immunoblotting experiments. For fluorescent labelling, gels were fixed in $7.5 \%(\mathrm{v} / \mathrm{v})$ acetic acid and $10 \%$ (v/v) methanol, washed for 30 min with $35 \mathrm{mM}$ sodium hydrogen carbonate and $300 \mathrm{mM}$ sodium carbonate, stained for $1 \mathrm{~h}$ with a 1:200 dilution of the Deep Purple stock solution, and then destained for twice $15 \mathrm{~min}$ using 7.5\% (v/v) acetic acid (Mackintosh et al., 2003). Colloidal Coomassie Blue staining of slab gels was carried out by the method of Neuhoff et al. (1988). The two-dimensional muscle protein pattern of young adult versus senescent gastrocnemius samples was 
assessed with a Typhoon Trio variable mode imager from Amersham Biosciences/GE Healthcare. Cropping of gel images was carried out with ImageQuant TL software.

\section{Mass spectrometric peptide fingerprinting analysis}

Peptide mass fingerprinting analysis was performed with trypsinated fragments using an Ettan MALDI-ToF Pro instrument from Amersham Biosciences, as recently described in detail (Donoghue et al., 2005; Doran et al., 2006a). For the unequivocal identification of $\alpha \mathrm{BC}$, Colloidal Coomassie Blue-stained 2-D protein spots were excised and gel plugs placed in pre-siliconised Eppendorf tubes to be desalted, destained, washed, dried, digested and mixed with matrix by standard methodology (Doran et al., 2006b). For protein digestion, trypsination was carried out at $37^{\circ} \mathrm{C}$ for $60 \mathrm{~min}$ with a solution containing $1 \mu \mathrm{g}$ sequencing-grade trypsin per $20 \mu 150 \mathrm{mM} \mathrm{NH}_{4} \mathrm{HCO}_{3}$. An equal volume of matrix solution containing $5 \mathrm{mg} / \mathrm{ml} \alpha$-cyano-4-hydroxycinnamic acid in $50 \%(\mathrm{v} / \mathrm{v})$ acetonitrile $/ 0.1 \%(\mathrm{v} / \mathrm{v})$ trifluoroacetic acid was used to elute the trypsin-treated peptide mixture onto the sample plate. MALDI-ToF mass spectra were recorded in the positive reflector mode with an accelerating voltage of $20 \mathrm{kV}$ and pulsed extraction on (focus mass of 2500). Both internal standard peptides (autolysis products of trypsin at $221.104 \mathrm{~m} / \mathrm{z}$ and $842.50 \mathrm{~m} / \mathrm{z}$ ) and external standard peptides (Peptidemix-1 from Laserbiolabs containing peaks ranging from $1046.5 \mathrm{~m} / \mathrm{z}$ to $2465.10 \mathrm{~m} / \mathrm{z}$ ) were employed for calibration of the mass spectrometer. Ettan MALDI evaluation software was used for the analysis of mass spectra and the ProFound database search engine for peptide mass fingerprints was employed for the identification of individual muscle protein species.

\section{Immunoblot analysis}

In order to determine the abundance of $\alpha \mathrm{BC}$, cvHsp and related Hsps in young adult versus senescent gastrocnemius samples, 1-D or 2-D electrophoretically separated muscle protein complements were transferred to Immobilon NC-pure nitrocellulose membranes employing a Transblot Cell system (Biorad Laboratories, Hemel Hempstead, Herts., UK) at $100 \mathrm{~V}$ for $70 \mathrm{~min}$ (Dowling et al., 2004). In the case of large $24 \mathrm{~cm} \times 24 \mathrm{~cm}$ 2-D slabs, gels were cut into four $6 \mathrm{~cm} \times 6 \mathrm{~cm}$ areas for individual and efficient transfer to nitrocellulose sheets. Following evaluation of transfer efficiency by Ponceau-S Red staining and subsequent washing with phosphatebuffered saline (PBS), nitrocellulose sheets were blocked with milk protein and then incubated with a suitably diluted primary antibody for $3 \mathrm{~h}$ (Harmon et al., 2001).
Blots were then washed, incubated with peroxidaseconjugated secondary antibodies, washed again, and immunodecoration was visualized by enhanced chemiluminescence (ECL) using the Pierce Supersignal ECL kit. Our laboratory has previously optimized 2-D immunoblotting with respect to standardization and a linear relationship between ECL signal intensity and exposure time (Doran et al., 2006a, b). A Typhoon Trio variable mode imager from Amersham Biosciences/GE Healthcare with ImageQuant TL software was employed to compare the relative immunolabelling intensity of 1-D bands or 2-D protein spots, whereby the statistical evaluation of densitometric data was carried out with Graphpad Prism 5 software (Graphpad Software Inc., San Diego, CA).

\section{Confocal microscopy}

Transverse cryosections from gastrocnemius muscle with an approximate $10 \mu \mathrm{m}$ thickness were prepared on a Thermo Shandon Cryotome (Life Science International Ltd., Cheshire, UK) and mounted on Superfrost Plus positively charged microscope slides (Mulvey et al., 2005). For optimum immunolabelling, tissue sections were incubated overnight at $4{ }^{\circ} \mathrm{C}$ with suitably diluted primary antibodies, washed in PBS and incubated for $30 \mathrm{~min}$ at $25^{\circ} \mathrm{C}$ with secondary antibodies that had been conjugated to Alexa Fluor 488 or Alexa Fluor 594. Antibody labelling for the sarcolemmal marker $\beta$-dystroglycan or the extracellular matrix component laminin was employed to outline the periphery of individual muscle cells. For labelling the position of nuclei within muscle fibres, cryosections were incubated with DAPI (Dowling et al., 2004). Image acquisition was performed with an Olympus FluoView FV1000 confocal laser scanning microscope (Olympus Life and Material Science Europe, Hamburg, Germany) using the Olympus FluoView Version 1.3c software package.

\section{Results}

\section{Gel electrophoretic analysis of $\alpha \mathrm{BC}$ and cvHsp in aged muscle fibres}

Previous studies have shown drastically changed levels of $\alpha \mathrm{BC}$ and cvHsp during muscle fibre transformation and in muscular dystrophy (Neufer and Benjamin, 1996; Donoghue et al., 2005; Doran et al., 2006a). It was therefore of considerable interest to determine the fate of these key sHsps in aged skeletal muscle. Highresolution 2-D gel electrophoresis was combined with sensitive total protein staining methods in order to evaluate the protein expression pattern of the soluble skeletal muscle proteome from young adult versus 
senescent rats. Crude tissue extracts were used without prior subcellular fractionation steps, which should have kept the introduction of potential artefacts in this comparative analysis to a minimum. Although 2-D gel electrophoretic techniques can separate hundreds to thousands of individual spots, certain protein species are under-represented including membrane-associated proteins, components with extreme $\mathrm{p} I$ values, low-abundance peptides and proteins with a very high molecular mass. However, since Hsps are soluble proteins, gel electrophoresis and immunoblotting presented itself as suitable methods for the identification and quantitation of $\alpha \mathrm{BC}$ and cvHsp in an animal model of sarcopenia. In comparison with established gel electrophoretic data banks (Sanchez et al., 2001; Yan et al., 2001; Gelfi et al., 2006), the position of both sHsps was determined following 2-D separation. As illustrated in Fig. 1A-D, both colloidal Coomassie Blue staining and fluorescent Deep Purple labelling revealed a relatively comparable protein expression pattern for high-abundance proteins in young adult versus old muscle. In contrast, protein spots corresponding to the two sHsps of interest exhibited a clear increase in senescent fibres (Fig. 2B and D) as compared to preparations from young adults (Fig. 2A and C). Based on previous gel electrophoretic studies, as recently reviewed by Doran et al. (2007), the spot pattern shown in the enlarged images of Fig. 2 agree with international data banks and showed the

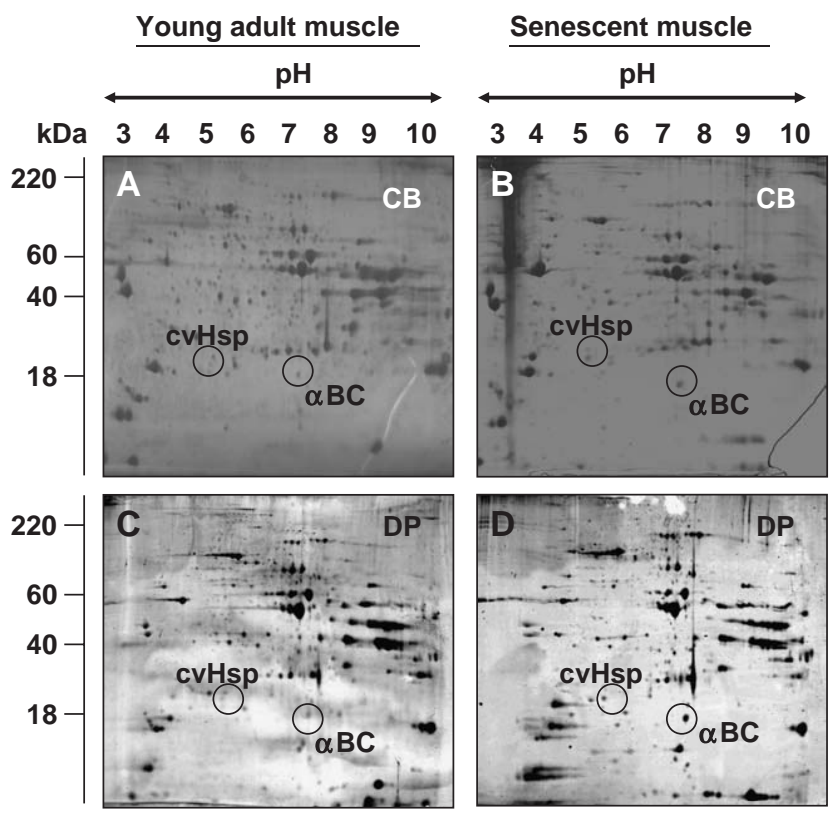

Fig. 1. Comparative 2-D gel electrophoretic analysis of young adult $(\mathrm{A}, \mathrm{C})$ versus aged $(\mathrm{B}, \mathrm{D})$ gastrocnemius rat muscle. Circles mark protein spots that correspond to $\alpha \mathrm{B}$-crystallin $(\alpha \mathrm{BC})$ and the cardiovascular Hsp (cvHsp). Following gel electrophoretic separation, total protein staining was performed with colloidal Coomassie Blue $(\mathrm{CB}$; A, B) or the fluorescent dye Deep Purple (DP; C, D).

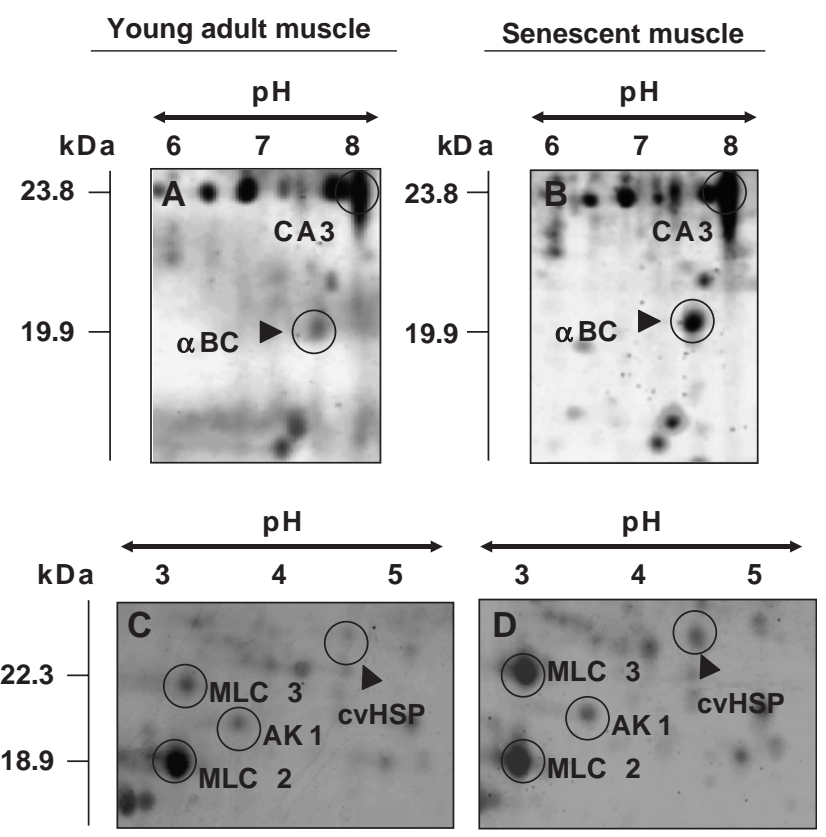

Fig. 2. Comparative 2-D gel electrophoretic analysis of $\alpha \mathrm{B}$ crystallin $(\alpha \mathrm{BC})$ and cardiovascular heat shock protein of young adult $(\mathrm{A}, \mathrm{C})$ versus senescent $(\mathrm{B}, \mathrm{D})$ gastrocnemius rat muscle. Circles mark protein spots that correspond to $\alpha \mathrm{BC}$ and the cardiovascular Hsp (cvHSP). For comparative purposes, the electrophoretic mobility of well-established landmark skeletal muscle proteins is shown, including the CA3 isoform of carbonic anhydrase (CA3), the myosin light chains MLC2 and MLC3, and the AK1 isoform of adenylate kinase (AK1). Following gel electrophoretic separation, total protein staining was performed with the fluorescent dye Deep Purple (A, B) or colloidal Coomassie Blue staining (C, D).

electrophoretic mobility of well-established landmark skeletal muscle proteins. This included the CA3 isoform of carbonic anhydrase (Fig. 2A and B), myosin light chains MLC2 and MLC3 (Fig. 2C and D), as well as the AK1 isoform of adenylate kinase (Fig. 2C and D).

\section{Mass spectrometric identification of $\alpha \mathrm{BC}$ from skeletal muscle}

In order to unequivocally identify the approximately $20-\mathrm{kDa}$ protein spot separated by 2-D gel electrophoresis in the $\mathrm{pH} 7-8$ range, peptide mass fingerprinting analysis was performed. With the help of matrix-assisted laser desorption ionization time-of-flight (MALDI-ToF) mass spectrometry, the protein was demonstrated to be $\alpha \mathrm{BC}(19.95 \mathrm{kDa}$; $I$ 6.84; gi|30387800|). Fig. 3A shows the mass spectrometric spectrum of $\alpha \mathrm{BC}$ and lists the masses of the tryptic fragments that correlate with the amino acid sequence of this sHsp. The coverage of the entire sequence by the MALDI-ToF-identified peptides was approximately $49 \%$ (Fig. 3B), which gives 
A

MALDI-ToF MS spectrum of $\alpha B C$-containing 2-D spot

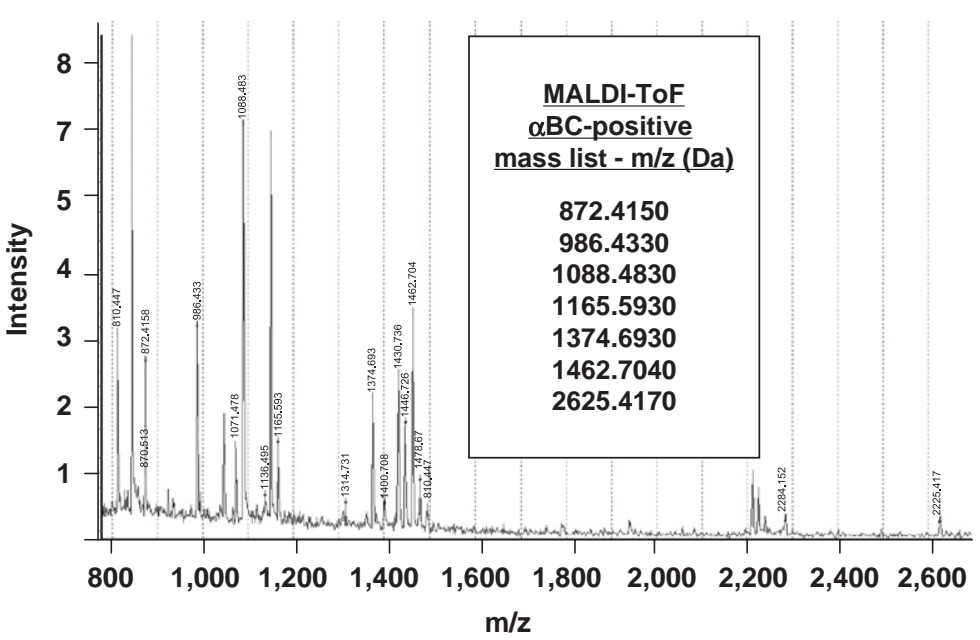

B

Peptide mass fingerprint of $\alpha \mathrm{BC}$ from in-gel digest

\begin{tabular}{|l}
\hline IPDIAIHHPWIRRPFFPFHSPSRLFDQFFGEHLLESDLFSTATSLSPFYL \\
RPPSFLRAPSWIDTGLSEMRMEKDRFSVNLDVKHFSPEELKVKVLGD \\
VIEVHGKHEERQDEHGFISREFHRKYRIPADVDPLTITSSLSSDGVLTV \\
NGPRKQASGPERTIPITREEKPAVTAAPK K \\
\hline \hline Amino acid sequence of gi|30387800| alpha B-crystallin Rattus sp.
\end{tabular}

Fig. 3. Matrix-assisted laser desorption ionization time-of-flight (MALDI-ToF) mass spectrometric identification $\alpha \mathrm{B}-\mathrm{crystallin}$ $(\alpha \mathrm{BC})$ from skeletal muscle. The mass list of $\alpha \mathrm{BC}$-positive peptides revealed an approximate $49 \%$ coverage of the $\alpha \mathrm{BC}$ amino acid sequence.

this finding a high confidence for a positive identification. In contrast to the relatively distinct $\alpha \mathrm{BC}$-containing spot (Fig. 2), peptide fingerprinting of gel plugs corresponding to cvHsp did not result in mass spectrometric data with a sufficient expectation value for a positive identification of this protein species (not shown). The reason for this is probably the relative low abundance of cvHsp in skeletal muscle (Fig. 2). A successful mass spectrometric identification of cvHsp has only been reported for diaphragm muscle, which appears to contain considerably higher levels of this sHsp as compared to limb muscle (Doran et al., 2006a). Thus, immunoblotting was employed as an alternative biochemical method to identify cvHsp in muscle and quantitate the expression levels of both sHsps in young adult versus aged fibres.

\section{Immunoblot analysis of $\alpha \mathrm{BC}$ and cvHSP in aged muscle fibres}

The 10 described mammalian sHsps show high homology in the $\alpha$-crystallin domain (Stamler et al., 2005). Hence, in order to properly perform an immunoblotting and immunofluorescence survey of $\alpha \mathrm{BC}$ and related sHsps, antibodies with an extremely high specificity for their respective sHsp had to be employed that do not exhibit cross-reactivity with any homologous sequences. The antibodies used against $\alpha \mathrm{BC}$ and cvHsp recognize amino acids 1-10 (MDIAIHHPWI) and 52-77 (FGSFMRPHSEPLAFPARPGGAGNIKT) in the peptide sequences of HspB5 and HspB7, respectively. There is neither an overlap between these two domains, nor any sequence homology with the more carboxy-terminal $\alpha$-crystallin domain of approximately 90 residues (Stamler et al., 2005). See the comparative sequencing analysis of $\alpha$-crystallin-related sHsps by Kappe et al. (2003) for a detailed alignment of all 10 mammalian sHsps. Therefore, the immunoblotting data shown in Fig. 4 should reflect an accurate estimation of expression levels of these two key sHsps in young adult versus old muscle. The graphical presentation of immunodecoration (Fig. 4G and $\mathrm{H}$ ) clearly suggests an increase in both $\alpha \mathrm{BC}$ and cvHsp in senescent (Fig. 4B and D) as compared to young adult (Fig. 4A and C) fibres, which agrees with the gel electrophoretic analysis of these sHsps shown above (Figs. 1 and 2). To correlate the immunoblotting data to the gel electrophoretic procedure, the Deep Purple-stained landmark spot representing creatine kinase is shown in Fig. 4E and F, 


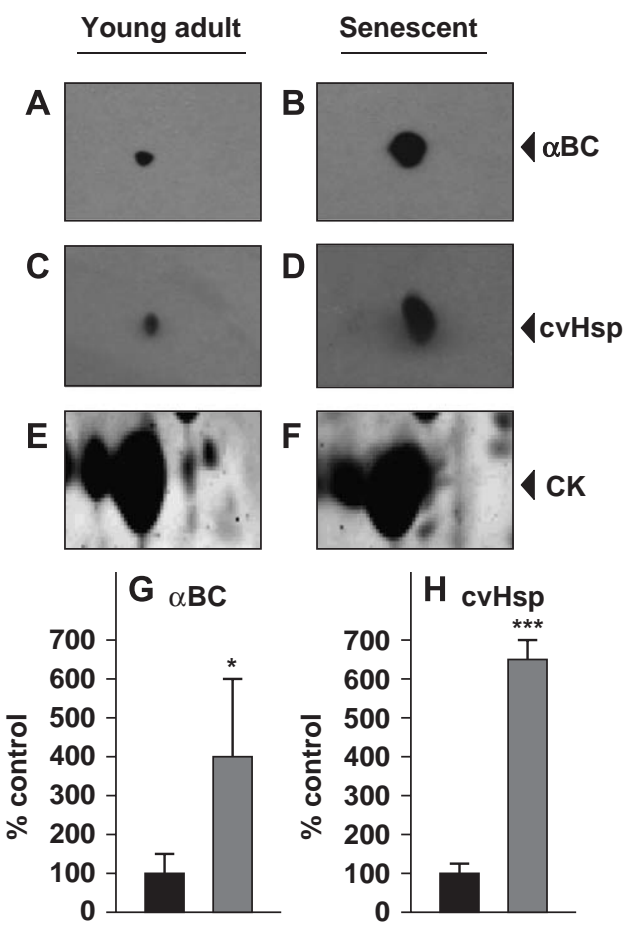

Fig. 4. Two-dimensional immunoblot analysis of $\alpha \mathrm{B}$-crystallin $(\alpha \mathrm{BC} ; \mathrm{A}, \mathrm{B})$ and cardiovascular heat shock protein (cvHsp; C, $\mathrm{D})$ in young adult $(\mathrm{A}, \mathrm{C})$ versus senescent $(\mathrm{B}, \mathrm{D})$ muscle. To correlate immunoblotting to the equal expression levels of a landmark spot in Deep Purple-stained slab gels, the twodimensional protein spot representing the abundant muscle enzyme creatine kinase (CK) is shown in (E; young adult) and (F; senescent). The comparative immunoblotting data were quantitated $(\mathrm{G}, \mathrm{H})$ and statistically evaluated using an unpaired Student's $t$-test $(n=5 ; * p<0.05 ; * * *<0.001)$.

which clearly demonstrated an equal distribution of this abundant muscle enzyme in young adult versus old muscle. The immunoblotting with antibodies to other Hsps revealed a differential effect of aging on these stress proteins. While Hsp25 showed comparable expression levels (Fig. 5C and D), Hsp20 and Hsp90 were increased in aged fibres (Fig. 5A, B, I, J), and Hsp60 and Hsp70 exhibited a reduced abundance in senescent muscle (Fig. 5E, F, G, H). The graphical presentation of the immunodecoration of these five Hsps is shown in Fig. $5 \mathrm{~K}-\mathrm{O}$. To confirm the findings from the 2-D immunodecoration survey, the expression of key Hsps was also evaluated by conventional 1-D immunoblotting. As illustrated in the representative immunoblots in Fig. 6A-E and their graphical presentation in Fig. $6 \mathrm{~F}-\mathrm{J}$, the results obtained with both immunoblotting techniques agree relatively well with each other (Figs. 4-6). While the concentration levels of $\alpha \mathrm{BC}$, cvHsp and Hsp20 are clearly increased in aged fibres, the expression of the high-molecular-mass stress proteins Hsp60 and Hsp70 was decreased in older muscle.

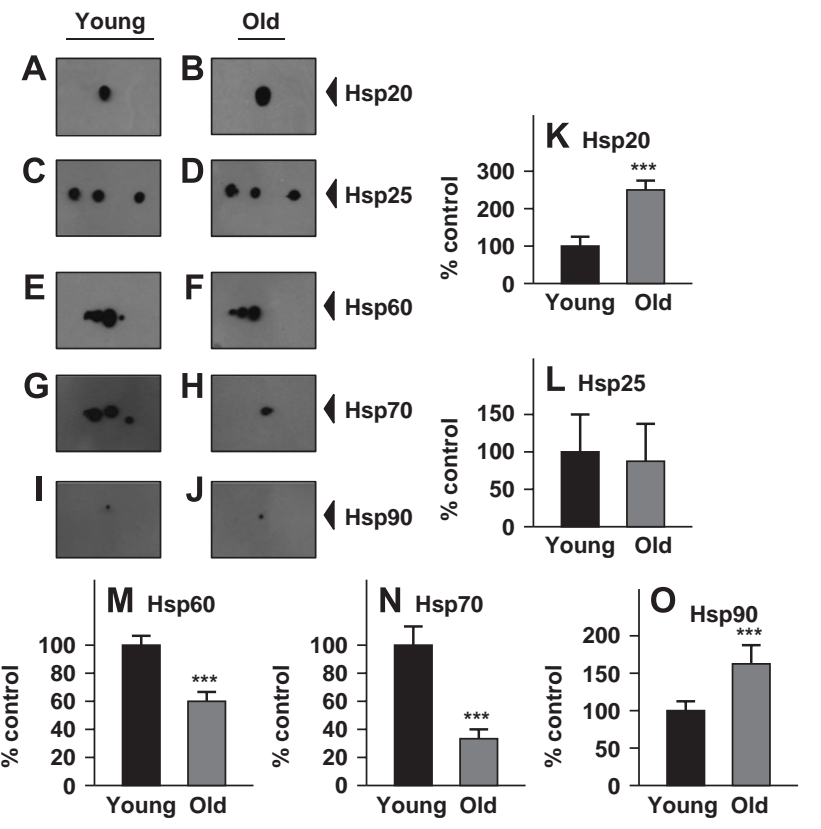

Fig. 5. Two-dimensional immunoblot analysis of Hsp20 (A, B), Hsp25 (C, D), Hsp60 (E, F), Hsp70 (G, H), and Hsp90 $(\mathrm{I}, \mathrm{J})$ in young adult $(\mathrm{A}, \mathrm{C}, \mathrm{E}, \mathrm{G}, \mathrm{I})$ versus senescent $(\mathrm{B}, \mathrm{D}, \mathrm{F}$, $\mathrm{H}, \mathrm{J})$ muscle. The comparative immunoblotting data were quantitated $(\mathrm{K}-\mathrm{O})$ and statistically evaluated using an unpaired Student's $t$-test $(n=5 ; * * * p<0.001)$.

\section{Immunofluorescence survey of $\alpha \mathrm{BC}$ and cvHsp in aged muscle fibres}

Confocal microscopy was used for Hsp localization studies employing primary antibodies to the two sHsps of interest and fluorescently labelled secondary antibodies. The periphery of skeletal muscle fibres in transverse cryosections was visualized by immunolabelling of surface markers. This included the extracellular matrix protein laminin (Fig. 7A and B) and the sarcolemmal glycoprotein $\beta$-dystroglycan (Fig. 7I and J). The position of nuclei was determined by standard DAPI staining (Fig. $7 \mathrm{C}, \mathrm{D}, \mathrm{K}, \mathrm{L}$ ). Comparative immunofluorescence labelling of $\alpha \mathrm{BC}$ and cvHsp revealed increased levels for both sHsps in older fibres (Fig. 7E, F, M, N). Panels with overlapping images for DAPI staining and immunodecoration of sHsps are shown in Fig. $7 \mathrm{G}, \mathrm{H}, \mathrm{O}, \mathrm{P}$. Higher resolution images revealed a drastic increase of cvHsp in the region of the cytosol and contractile apparatus, as well as colocalization with the sarcolemmal membrane marker $\beta$-dystroglycan in aged fibres, as compared to young adult muscle (Fig. 8A and B). In contrast to young adult muscle, more intense $\alpha \mathrm{BC}$ labelling was observed that co-localized with the surface marker laminin in aged fibres, indicating increased levels of this sHsp in the muscle periphery of senescent muscle (Fig. 8C and D). The elevated density of $\alpha \mathrm{BC}$ and cvHsp in aged fibres, as revealed by confocal microscopy, agreed with the gel 

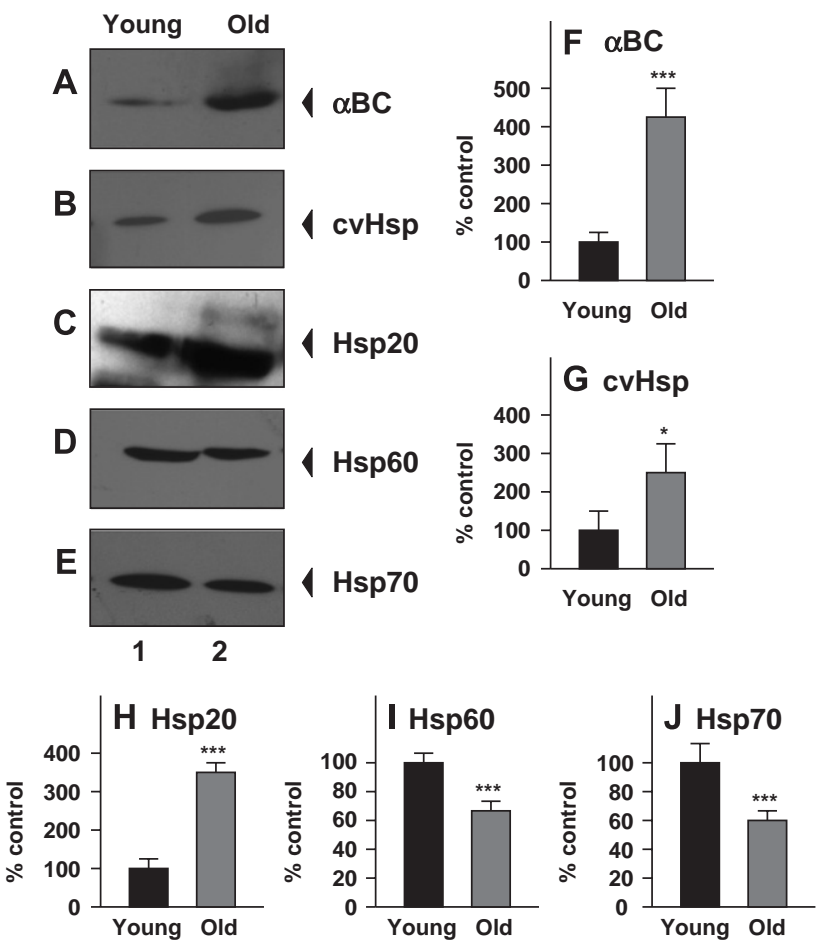

Fig. 6. One-dimensional immunoblot analysis of $\alpha \mathrm{B}$-crystallin $(\alpha \mathrm{BC} ; \mathrm{A})$, the cardiovascular heat shock protein (cvHsp; B) and other key heat shock proteins, Hsp20 (C), Hsp60 (D) and Hsp70 (E) in young adult (lane 1) versus senescent (lane 2) muscle. The comparative immunoblotting data were quantitated $(\mathrm{F}-\mathrm{J})$ and statistically evaluated using an unpaired Student's $t$-test $(n=4 ; * p<0.05 ; * * * p<0.001)$.

electrophoretic analysis and immunoblotting of both sHsps outlined above in Figs. 1-6.

\section{Discussion}

The protein family of sHsps is believed to play a crucial protective role in a variety of tissues by binding denatured proteins. In contrast to high-molecular-mass Hsps, sHsps represent ATP-independent chaperones (de Jong et al., 1993). In response to cellular stress, polydisperse assemblies of sHsps appear to disintegrate into smaller subunits, which is followed by binding to unfolding substrate and then reforming into larger complexes (Stamler et al., 2005). Here, we have investigated the fate of two essential sHsps, $\alpha \mathrm{BC}$ and cvHsp (Kappe et al., 2003), in aged skeletal muscle fibres. Two-dimensional gel electrophoretic analysis using the highly sensitive fluorescent total protein dye Deep Purple and colloidal Coomassie Blue staining, in combination with immunoblotting and immunofluorescence microscopy, has revealed a drastic increase of both sHsps in senescent gastrocnemius muscle. Since during fibre aging a variety of molecular and cellular changes occur including a fibre type shifting-induced remodelling of the contractile apparatus and a transition to aerobicoxidative metabolism (Doherty, 2003), the up-regulation of a distinct sub-population of sHsps may represent an auto-protective mechanism. Age-induced alterations in filament structure and contractile elements are associated with increased levels of denatured muscle proteins (Navarro et al., 2001; Vandervoort, 2002). In order to prevent the deleterious accumulation of non-functional protein aggregates, an elevated concentration of specific sHsps might counteract severe muscle damage. This idea would agree with previous studies on the role of Hsps in normal and pathological skeletal muscle (Nishimura and Sharp, 2005).

The subfamily of small stress response chaperones is relatively abundant in muscle tissues (Golenhofen et al., 2004) and the $\alpha$-crystallin domain-containing proteins appear to be associated with the modulation of intermediate filament assembly (Nicholl and Quinlan, 1994). Several biochemical studies have shown that continuous contractile activity influences the abundance levels of $\alpha \mathrm{BC}$ (Neufer and Benjamin, 1996; Neufer et al., 1998; Donoghue et al., 2005). Hence, age-related damage to cytoskeletal filaments may trigger the increased synthesis of distinct chaperones, as shown in this study. The previously described shift of aged fibres to increased aerobic-oxidative metabolism was confirmed by the proteomic profiling of senescent fibres, which exhibited a drastic reduction in glycolytic enzymes (Piec et al., 2005). The fast-to-slow transition process during muscle aging involves major cellular restructuring (Doherty, 2003) and therefore requires the support of molecular chaperones to prevent a high degree of detrimental protein aggregation (Nishimura and Sharp, 2005). The most common neuromuscular disease, Duchenne muscular dystrophy, is associated with altered expression levels of major Hsps (Bornman et al., 1995). In analogy to the results presented in this study, the recent proteomic screening of the dystrophic diaphragm revealed a drastic increase in cvHSP in dystrophin-deficient fibres from the mutant $\mathrm{mdx}$ mouse (Doran et al., 2006a). Muscle wasting pathology seems to trigger the up-regulation of distinct sHsps. This might have important biomedical implications with respect to establishing novel diagnostic markers or developing alternative treatment regimes for common muscle disorders, such as sarcopenia.

Immunofluorescence labelling of aged muscle fibres also demonstrated an elevated expression of $\alpha \mathrm{BC}$ and cvHsp in senescent muscle. High levels of sHsps were found in the surface membrane and cytosolic region of aged fibres. Interestingly, translocation of $\alpha \mathrm{BC}$ to the nucleus of stressed myoblasts has previously been described by Adhikari et al. (2004). This study indicates that cvHsp and $\alpha \mathrm{BC}$ play a major role in preventing deleterious protein aggregation in the sarcolemma region, cytosol and contractile machinery (Melkani 

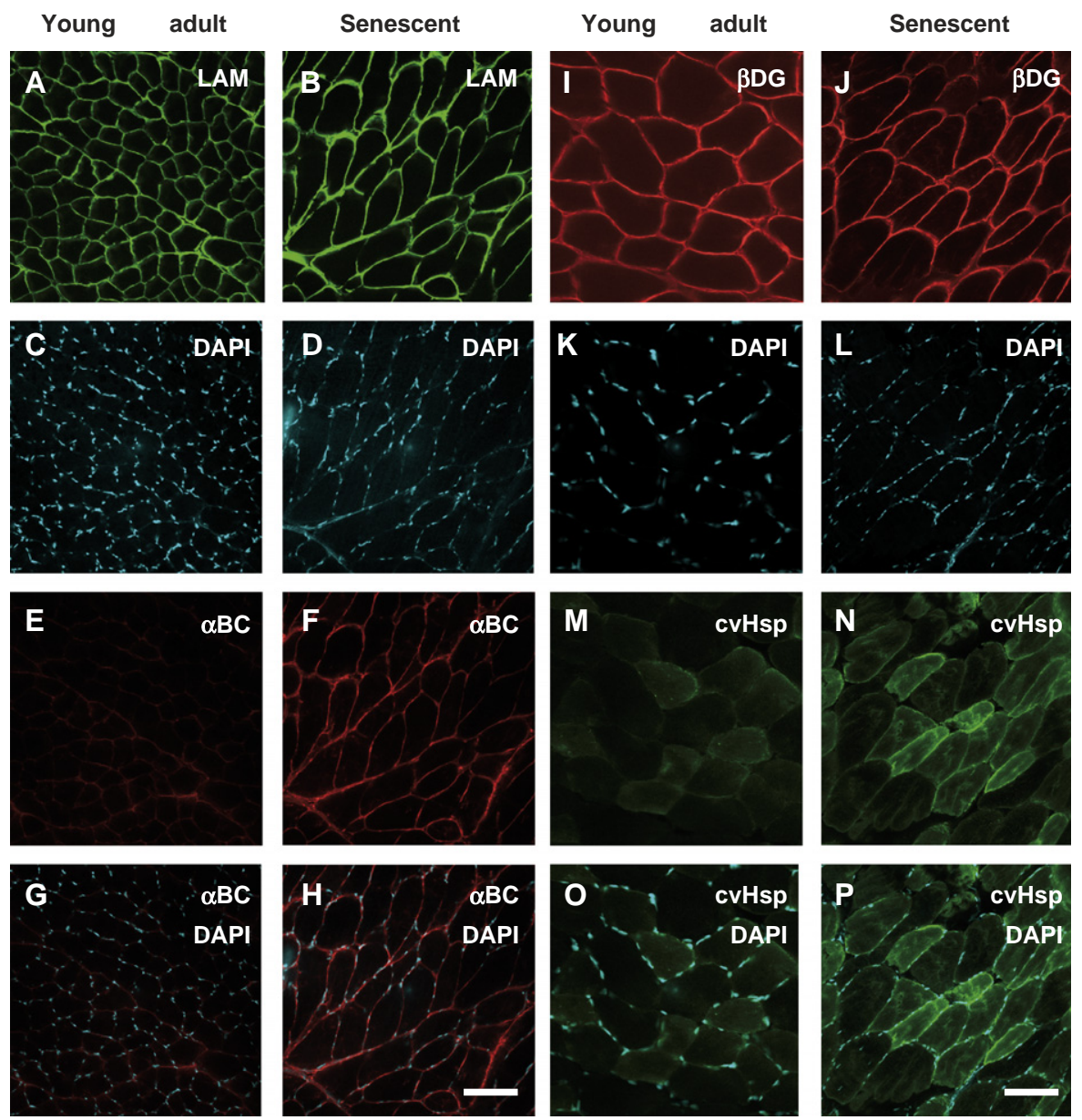

Fig. 7. Immunolocalization of $\alpha \mathrm{B}$-crystallin $(\alpha \mathrm{BC})$ and cardiovascular heat shock protein (cvHsp) in young adult and senescent skeletal muscle. LAM, laminin; $\beta$ DG, $\beta$-dystroglycan. Bars, $40 \mu \mathrm{m}$.

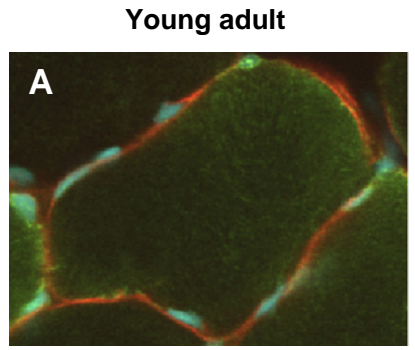

cvHsp / $\beta D G$ / DAPI

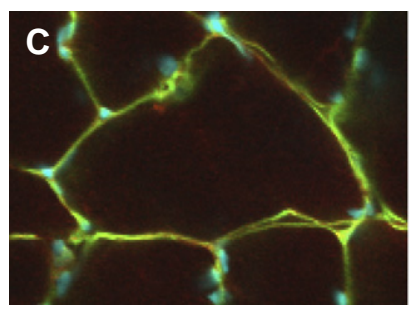

$\alpha B C /$ LAM/ DAPI

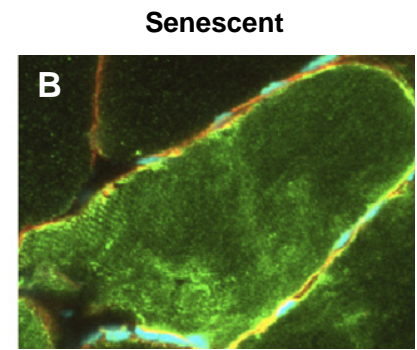

cvHsp / $\beta$ DG / DAPI

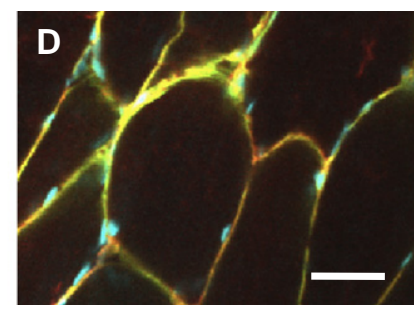

$\alpha B C /$ LAM/ DAPI

Fig. 8. Immunolocalization of $\alpha \mathrm{B}$-crystallin $(\alpha \mathrm{BC})$ and cardiovascular heat shock protein (cvHSP) in young adult and senescent skeletal muscle, and co-localization with laminin (LAM) and $\beta$-dystroglycan ( $\beta \mathrm{DG})$, respectively. Bar, $10 \mu \mathrm{m}$.

et al., 2006). That Hsps are of general importance for the maintenance of cellular integrity has been shown by numerous studies focusing on Hsp function in skeletal muscles, as reviewed by Nishimura and Sharp (2005). Especially Hsp70 was shown to play a pivotal role in maintaining fibre homeostasis by preventing excess apoptosis, stabilizing metabolic pathways and the facilitation of muscular adaptation processes (Liu et al., 2006). Since apoptosis is associated with increased muscular atrophy, the coordinated stress response appears to be essential for counteracting major muscle wasting during middle-age and senescence of skeletal muscles (Chung and $\mathrm{Ng}, 2006$ ). Importantly, overexpression of Hsp70 in the muscle of old transgenic mice protected fibres against age-related muscle dysfunction (McArdle et al., 2004; Broome et al., 2006). Consequently, a diminished Hsp70 response in aged muscle appears to be a major factor that causes age-dependent functional deficits (Vasilaki et al., 2002; McArdle et al., 2002). We could show here that the levels of both Hsp60 and Hsp70 are reduced in aged muscle. However, it is important to stress that monoclonal antibody BB70 used in this study binds both to the constitutive form 
(Hsc70/Hsp73) and the inducible form (Hsp70/Hsp72) of this important stress protein. Under normal conditions, Hsp72 is expressed at relatively low levels, while it may be highly induced following stress (Cvoro et al., 2004). A previous investigation by Locke (2000) has documented that the concentration of Hsp72 is not significantly different in adult versus aged soleus and gastrocnemius muscle. Studies by Naito et al. (2001) and Murlasits et al. (2006) compared the effect of resistance training on differently aged muscles. Although both young and old fibres are capable of increasing Hsp expression, the response was less robust in fastcontracting senescent muscle.

In conclusion, the up-regulation of distinct Hsps can be considered an auto-protective mechanism in degenerating muscle fibres. This study has clearly shown that the expression of two essential sHsps, $\alpha \mathrm{BC}$ and cvHsp, is increased during rat muscle aging, which agrees with a recent study by Yamaguchi et al. (2007) on aged human fibres. This knowledge can be useful for both improving diagnostic and/or therapeutic strategies. Since no proper diagnostic criteria exist yet for the differential diagnosis of severe sarcopenia versus mild age-related muscle weakness (Carmeli et al., 2002; Greenlund and Nair, 2003), the establishment of novel biomarkers of muscle degeneration may be helpful in developing diagnostic procedures with reliable indicators of aging-induced fibre degeneration. More importantly, since heat shock treatment of myoblasts was shown to improve their survival rate following transplantation in the experimental treatment of muscular dystrophy (Bouchentouf et al., 2004), the stress response in aged fibres may be exploitable as a new approach to counteract excessive muscle damage in sarcopenia of old age. The findings of this study suggest that the cell therapeutic or pharmacological enhancement of the heat shock response might be helpful for preventing age-related muscle wasting.

\section{Acknowledgements}

Research was supported by a principal investigator grant from Science Foundation Ireland (SFI-04/IN3/B614) and equipment grants from the Irish Health Research Board (HRB-EQ/2003/3, HRB-EQ/2004/2). The authors thank Dr. Ica Dix (Confocal Microscopy Unit, NUI Maynooth) for her expert technical assistance with immunofluorescence microscopy and Dr. Marina Lynch (Department of Physiology, Trinity College, Dublin) for her generous help obtaining young adult and aged rat muscle.

\section{References}

Adhikari, A.S., Rao, K.S., Rangaraj, N., Parnaik, V.K., Rao, C.M., 2004. Heat stress-induced localization of small heat shock proteins in mouse myoblasts: intranuclear lamin $\mathrm{A} / \mathrm{C}$ speckles as target for alphaB-crystallin and Hsp25. Exp. Cell Res. 299, 393-403.

Alnaqeeb, M.A., Goldspink, G., 1987. Changes in fibre type, number and diameter in developing and ageing skeletal muscle. J. Anat. 153, 31-45.

Amin, J., Ananthan, J., Voellmy, R., 1988. Key features of heat shock regulatory elements. Mol. Cell. Biol. 8, 3761-3769.

Anckar, J., Sistonen, L., 2007. Heat shock factor 1 as a coordinator of stress and developmental pathways. Adv. Exp. Med. Biol. 594, 78-88.

Bornman, L., Polla, B.S., Lotz, B.P., Gericke, G.S., 1995. Expression of heat shock/stress proteins in Duchenne muscular dystrophy. Muscle Nerve 18, 23-31.

Bouchentouf, M., Benabdallah, B.F., Tremblay, J.P., 2004. Myoblast survival enhancement and transplantation success improvement by heat-shock treatment in $\mathrm{mdx}$ mice. Transplantation 77, 1349-1356.

Broome, C.S., Kayani, A.C., Palomero, J., Dillmann, W.H., Mestril, R., Jackson, M.J., McArdle, A., 2006. Effect of lifelong overexpression of HSP70 in skeletal muscle on agerelated oxidative stress and adaptation after nondamaging contractile activity. FASEB J. 20, 1549-1551.

Carmeli, E., Coleman, R., Reznick, A.Z., 2002. The biochemistry of aging muscle. Exp. Gerontol. 37, 477-489.

Chung, L., Ng, Y.C., 2006. Age-related alterations in expression of apoptosis regulatory proteins and heat shock proteins in rat skeletal muscle. Biochim. Biophys. Acta 1762, 103-109.

Cutlip, R.G., Baker, B.A., Geronilla, K.B., Kashon, M.L., $\mathrm{Wu}$, J.Z., 2007. The influence of velocity of stretch and dash shortening contractions on muscle performance during chronic exposure: age effects. Appl. Physiol. Nutr. Metab. 32, 443-453.

Cvoro, A., Korac, A., Matic, G., 2004. Intracellular localization of constitutive and inducible heat shock protein 70 in rat liver after in vivo heat stress. Mol. Cell. Biochem. 265, 27-35.

de Jong, W.W., Leunissen, J.A., Voorter, C.E., 1993. Evolution of the alpha-crystallin/small heat-shock protein family. Mol. Biol. Evol. 10, 103-126.

Doherty, T.J., 2003. Aging and sarcopenia. J. Appl. Physiol. 95, 1717-1727.

Donoghue, P., Doran, P., Dowling, P., Ohlendieck, K., 2005. Differential expression of the fast skeletal muscle proteome following chronic low-frequency stimulation. Biochim. Biophys. Acta 1752, 166-176.

Doran, P., Dowling, P., Lohan, J., McDonnell, K., Poetsch, S., Ohlendieck, K., 2004. Subproteomics analysis of $\mathrm{Ca}^{2+}$. binding proteins demonstrates decreased calsequestrin expression in dystrophic mouse skeletal muscle. Eur. J. Biochem. 271, 3943-3952.

Doran, P., Martin, G., Dowling, P., Jockusch, H., Ohlendieck, K., 2006a. Proteome analysis of the dystrophin-deficient MDX diaphragm reveals a drastic increase in the heat shock protein cvHSP. Proteomics 6, 4610-4621.

Doran, P., Dowling, P., Donoghue, P., Buffini, M., Ohlendieck, K., 2006b. Reduced expression of regucalcin in young and aged $\mathrm{mdx}$ diaphragm indicates abnormal 
cytosolic calcium handling in dystrophin-deficient muscle. Biochim. Biophys. Acta 1764, 773-785.

Doran, P., Donoghue, P., O’Connell, K., Gannon, J., Ohlendieck, K., 2007. Proteomic profiling of pathological and aged skeletal muscle fibres by peptide mass fingerprinting. Int. J. Mol. Med. 19, 547-564.

Dowling, P., Doran, P., Ohlendieck, K., 2004. Drastic reduction of sarcalumenin in Dp427 (dystrophin of $427 \mathrm{kDa}$ )-deficient fibres indicates that abnormal calcium handling plays a key role in muscular dystrophy. Biochem. J. 379, 479-488.

Dubin, R.A., Wawrousek, E.F., Piatigorsky, J., 1989. Expression of the murine alpha B-crystallin gene is not restricted to the lens. Mol. Cell. Biol. 9, 1083-10891.

Edstrom, L., Larsson, L., 1987. Effects of age on contractile and enzyme-histochemical properties of fast- and slowtwitch single motor units in the rat. J. Physiol. 392, 129-145.

Fontaine, J.M., Sun, X., Benndorf, R., Welsh, M.J., 2005. Interactions of HSP22 (HSPB8) with HSP20, alphaBcrystallin, and HSPB3. Biochem. Biophys. Res. Commun. 337, 1006-1011.

Gelfi, C., Vigano, A., De Palma, S., Ripamonti, M., Begum, S., Cerretelli, P., Wait, R., 2006. 2-D protein maps of rat gastrocnemius and soleus muscles: a tool for muscle plasticity assessment. Proteomics 6, 321-340.

Golenhofen, N., Perng, M.D., Quinlan, R.A., Drenckhahn, D., 2004. Comparison of the small heat shock proteins alphaB-crystallin, MKBP, HSP25, HSP20, and cvHSP in heart and skeletal muscle. Histochem. Cell Biol. 122, 415-425.

Greenlund, L.J., Nair, K.S., 2003. Sarcopenia - consequences, mechanisms, and potential therapies. Mech. Ageing Dev. 124, 287-299.

Harmon, S., Froemming, G.R., Leisner, E., Pette, D., Ohlendieck, K., 2001. Low-frequency stimulation of fast muscle affects the abundance of $\mathrm{Ca}(2+)$-ATPase but not its oligomeric status. J. Appl. Physiol. 90, 371-379.

Haslbeck, M., Franzmann, T., Weinfurtner, D., Buchner, J., 2005. Some like it hot: the structure and function of small heat-shock proteins. Nat. Struct. Mol. Biol. 12, 842-846.

Horwitz, J., 2000. The function of alpha-crystallin in vision. Semin. Cell Dev. Biol. 11, 53-60.

Horwitz, J., 2003. Alpha-crystallin. Exp. Eye Res. 76, 145-153.

Ikeda, R., Yoshida, K., Ushiyama, M., Yamaguchi, T., Iwashita, K., Futagawa, T., Shibayama, Y., Oiso, S., Takeda, Y., Kariyazono, H., Furukawa, T., Nakamura, K., Akiyama, S., Inoue, I., Yamada, K., 2006. The small heat shock protein alphaB-crystallin inhibits differentiationinduced caspase 3 activation and myogenic differentiation. Biol. Pharm. Bull. 29, 1815-1819.

Iwaki, T., Kume-Iwaki, A., Goldman, J.E., 1990. Cellular distribution of alpha B-crystallin in non-lenticular tissues. J. Histochem. Cytochem. 38, 31-39.

Kanski, J., Hong, S.J., Schoneich, C., 2005. Proteomic analysis of protein nitration in aging skeletal muscle and identification of nitrotyrosine-containing sequences in vivo by nanoelectrospray ionization tandem mass spectrometry. J. Biol. Chem. 280, 24261-24266.
Kappe, G., Franck, E., Verschuure, P., Boelens, W.C., Leunissen, J.A., de Jong, W.W., 2003. The human genome encodes 10 alpha-crystallin-related small heat shock proteins: HspB1-10. Cell Stress Chaperones 8, 53-61.

Koh, T.J., 2002. Do small heat shock proteins protect skeletal muscle from injury? Exerc. Sport Sci. Rev. 30, 117-121.

Koh, T.J., Escobedo, J., 2004. Cytoskeletal disruption and small heat shock protein translocation immediately after lengthening contractions. Am. J. Physiol. Cell Physiol. 286, C713-C722.

Krief, S., Faivre, J.F., Robert, P., Le Douarin, B., BrumentLarignon, N., Lefrere, I., Bouzyk, M.M., Anderson, K.M., Greller, L.D., Tobin, F.L., Souchet, M., Bril, A., 1999. Identification and characterization of cvHsp. A novel human small stress protein selectively expressed in cardiovascular and insulin-sensitive tissues. J. Biol. Chem. 274, 36592-36600.

Larsson, L., Edstrom, L., 1986. Effects of age on enzymehistochemical fibre spectra and contractile properties of fast- and slow-twitch skeletal muscles in the rat. J. Neurol. Sci. 76, 69-89.

Larsson, L., Ansved, T., Edstrom, L., Gorza, L., Schiaffino, S., 1991. Effects of age on physiological, immunohistochemical and biochemical properties of fast-twitch single motor units in the rat. J. Physiol. 443, 257-275.

Lindquist, S., Craig, E.A., 1988. The heat-shock proteins. Annu. Rev. Genet. 22, 631-677.

Liu, Y., Steinacker, J.M., 2001. Changes in skeletal muscle heat shock proteins: pathological significance. Front. Biosci. 6, D12-D25.

Liu, Y., Gampert, L., Nething, K., Steinacker, J.M., 2006. Response and function of skeletal muscle heat shock protein 70. Front. Biosci. 11, 2802-2827.

Locke, M., 2000. Heat shock transcription factor activation and hsp72 accumulation in aged skeletal muscle. Cell Stress Chaperones 5, 45-51.

Mackintosh, J.A., Choi, H.Y., Bae, S.H., Veal, D.A., Bell, P.J., Ferrari, B.C., Van Dyk, D.D., Verrills, N.M., Paik, Y.K., Karuso, P., 2003. A fluorescent natural product for ultra sensitive detection of proteins in one-dimensional and two-dimensional gel electrophoresis. Proteomics 3, 2273-2288.

McArdle, A., Jackson, M.J., 2000. Exercise, oxidative stress and ageing. J. Anat. 197, 539-541.

McArdle, A., Vasilaki, A., Jackson, M., 2002. Exercise and skeletal muscle ageing: cellular and molecular mechanisms. Ageing Res. Rev. 1, 79-93.

McArdle, A., Dillmann, W.H., Mestril, R., Faulkner, J.A., Jackson, M.J., 2004. Overexpression of HSP70 in mouse skeletal muscle protects against muscle damage and agerelated muscle dysfunction. FASEB J. 18, 355-357.

Melkani, G.C., Cammarato, A., Bernstein, S.I., 2006. AlphaB-crystallin maintains skeletal muscle myosin enzymatic activity and prevents its aggregation under heat-shock stress. J. Mol. Biol. 358, 635-645.

Mulvey, C., Harno, E., Keenan, A., Ohlendieck, K., 2005. Expression of the skeletal muscle dystrophin-dystroglycan complex and syntrophin-nitric oxide synthase complex is severely affected in the type 2 diabetic Goto-Kakizaki rat. Eur. J. Cell Biol. 84, 867-883. 
Murlasits, Z., Cutlip, R.G., Geronilla, K.B., Rao, K.M., Wonderlin, W.F., Always, S.E., 2006. Resistance training increases heat shock protein levels in skeletal muscle of young and old rats. Exp. Gerontol. 41, 398-406.

Naito, H., Powers, S.K., Demirel, H.A., Aoki, J., 2001. Exercise training increases heat shock protein in skeletal muscles of old rats. Med. Sci. Sports Exerc. 33, 729-734.

Narberhaus, F., 2002. Alpha-crystallin-type heat shock proteins: socializing minichaperones in the context of a multichaperone network. Microbiol. Mol. Biol. Rev. 66, 64-93.

Navarro, A., Lopez-Cepero, J.M., Sanchez del Pino, M.J., 2001. Skeletal muscle and aging. Front. Biosci. 6, D26-D44.

Neufer, P.D., Benjamin, I.J., 1996. Differential expression of B-crystallin and Hsp27 in skeletal muscle during continuous contractile activity. Relationship to myogenic regulatory factors. J. Biol. Chem. 271, 24089-24095.

Neufer, P.D., Ordway, G.A., Williams, R.S., 1998. Transient regulation of c-fos, alpha B-crystallin, and hsp70 in muscle during recovery from contractile activity. Am. J. Physiol. 274, C341-C346.

Neuhoff, V., Arold, N., Taube, D., Ehrhardt, W., 1988. Improved staining of proteins in polyacrylamide gels including isoelectric focusing gels with clear background at nanogram sensitivity using Coomassie Brilliant Blue G-250 and R-250. Electrophoresis 9, 255-262.

Nicholl, I.D., Quinlan, R.A., 1994. Chaperone activity of alpha-crystallins modulates intermediate filament assembly. EMBO J. 13, 945-953.

Nishimura, R.N., Sharp, F.R., 2005. Heat shock proteins and neuromuscular disease. Muscle Nerve 32, 693-709.

Nolan, Y., Maher, F.O., Martin, D.S., Clarke, R.M., Brady, M.T., Bolton, A.E., Mills, K.H., Lynch, M.A., 2005. Role of interleukin-4 in regulation of age-related inflammatory changes in the hippocampus. J. Biol. Chem. 280, 9354-9362.

Oertel, M.F., May, C.A., Bloemendal, H., Lütjen-Drecoll, E., 2000. Alpha-B-crystallin expression in tissues derived from different species in different age groups. Ophthalmologica 214, 13-23.

Piec, I., Listrat, A., Alliot, J., Chambon, C., Taylor, R.G., Bechet, D., 2005. Differential proteome analysis of aging in rat skeletal muscle. FASEB J. 19, 1143-1145.

Sanchez, J.C., Chiappe, D., Converset, V., Hoogland, C., Binz, P.A., Paesano, S., Appel, R.D., Wang, S., Sennitt, M., Nolan, A., Cawthorne, M.A., Hochstrasser, D.F., 2001.
The mouse SWISS-2D PAGE database: a tool for proteomics study of diabetes and obesity. Proteomics 1, 136-163.

Stamler, R., Kappe, G., Boelens, W., Slingsby, C., 2005. Wrapping the alpha-crystallin domain fold in a chaperone assembly. J. Mol. Biol. 353, 68-79.

Sun, Y., MacRae, T.H., 2005. The small heat shock proteins and their role in human disease. FEBS J. 272, 2613-2627.

Sun, X., Fontaine, J.M., Rest, J.S., Shelden, E.A., Welsh, M.J., Benndorf, R., 2004. Interaction of human HSP22 (HSPB8) with other small heat shock proteins. J. Biol. Chem. 279, 2394-2402.

Takemoto, L., Boyle, D., 1998. The possible role of alphacrystallins in human senile cataractogenesis. Int. J. Biol. Macromol. 22, 331-337.

van Montfort, R., Slingsby, C., Vierling, E., 2001. Structure and function of the small heat shock protein/alphacrystallin family of molecular chaperones. Adv. Protein Chem. 59, 105-156.

van Rijk, A.F., Bloemendal, H., 2000. Alpha-B-crystallin in neuropathology. Ophthalmologica 214, 7-12.

Vandervoort, A.A., 2002. Aging of the human neuromuscular system. Muscle Nerve 25, 17-25.

Verschuure, P., Tatard, C., Boelens, W.C., Grongnet, J.F., David, J.C., 2003. Expression of small heat shock proteins HspB2, HspB8, Hsp20 and cvHsp in different tissues of the perinatal developing pig. Eur. J. Cell Biol. 82, 523-530.

Vasilaki, A., Jackson, M.J., McArdle, A., 2002. Attenuated HSP70 response in skeletal muscle of aged rats following contractile activity. Muscle Nerve 25, 902-905.

Vicart, P., Caron, A., Guicheney, P., Li, Z., Prevost, M.C., Faure, A., Chateau, D., Chapon, F., Tome, F., Dupret, J.M., Paulin, D., Fardeau, M.A., 1998. Missense mutation in the alphaB-crystallin chaperone gene causes a desminrelated myopathy. Nat. Genet. 20, 92-95.

Voellmy, R., Boellmann, F., 2007. Chaperone regulation of the heat shock protein response. Adv. Exp. Med. Biol. 594, 89-99.

Yamaguchi, T., Arai, H., Katayama, N., Ishikawa, T., Kikumoto, K., Atomi, Y., 2007. Age-related increase of insoluble, phosphorylated small heat shock proteins in human skeletal muscle. J. Gerontol. A 62, 481-489.

Yan, J.X., Harry, R.A., Wait, R., Welson, S.Y., Emery, P.W., Preedy, V., Dunn, M.J., 2001. Separation and identification of rat skeletal muscle proteins using two-dimensional gel electrophoresis and mass spectrometry. Proteomics 1, 424-434. 